\title{
Servidumbre y grandeza de la mediación en el ámbito del Derecho privado de la Unión Europea
}

\author{
Manuel María Zorrilla Ruiz \\ Catedrático emérito de la Universidad de Deusto \\ Ex-Presidente del Tribunal Superior de Justicia del País Vasco \\ Presidente de la Asociación de Jueces y Magistrados Jubilados de España
}

Recibido: 17.11 .2010

Aceptado: 20.12.2010

\begin{abstract}
Resumen: La mediación se puede convertir en la alternativa preferible para resolver los conflictos surgidos en materias de Derecho Civil y Mercantil. La mediación evita la rigidez de los procesos judiciales y facilita una respuesta rápida que no exige excesivos desembolsos a los sujetos del conflicto. La Unión Europea ha resaltado las funciones, responsabilidades y oportunidades de un método de solución alternativa de conflictos. Ofrece un panorama que, para promover la mediación, valora el consenso de los Estados miembros, la utilidad de ese equivalente jurisdiccional y la confianza depositada en su futuro. Las actividades académicas desenvueltas en el espacio de la Unión Europea señalan que los nuevos modelos de la mediación pueden eliminar un millón de conflictos anuales. La contribución del órgano denominado Steering Committé es necesaria para conocer las orientaciones y las críticas sobre las experiencias de la mediación.
\end{abstract}

Palabras clave: Desjudicialización, mediación, modos alternativos, órgano de orientación y de crítica, Unión Europea.

Abstract: The mediation may become the alternative preferable to resolve the conflicts about the questions of civil and commercial law. The mediation avoids the rigidity of the judicial procedures and gives a quick answer, without excessive expenses for the parts in collision. The European Union has emphasized the functions, the responsibilities and the opportunities in the method of Alternative Dispute Resolution. To promote the mediation, it offers a panoramic view favoured by the consensus of the Estates members, the profit of this judicial equivalent and the faith in the prosperity of its future. The academic activities developed in the field of the European Union, showed that the new models of mediation may eliminate one million disputes, annually. The task of the Steering Committee is capital to perceive the orientations and the judgements about the success of the civil and commercial mediation.

Key words: alternative dispute resolution, not justiciable, Steering Committee, European Union, mediation.

Sumario: 1. Significado de la intervención asignada a un órgano de orientación y de crítica sobre la importancia de la mediación y algunas de sus vicisitudes emergentes.-2. Novedosas funciones del órgano de orientación y de crítica -denominado Steering Commitee- en los análisis aconsejados por el carácter y el funcionamiento de la mediación sobre cues- 
tiones conflictivas de Derecho Civil y Mercantil.-3. Consideración conjunta de las peripecias y destaque actual del instituto de la mediación.

\section{Significado de la intervención asignada a un órgano de orientación y de crítica sobre la importancia de la mediación y algunas de sus vici- situdes emergentes}

Las reflexiones siguientes atañen a las iniciativas que, coordinadas con sensibilidad histórica y tenacidad elogiable, defienden la efectividad -neta expresión de la justicia material- de las orientaciones incorporadas a los instrumentos normativos de la UE (Unión Europea, cuyo Tratado constitutivo de 9 de febrero de 1.992 se conoce también con el nombre de Tratado de Maastricht) para informar de las ventajas de la mediación y difundir sus alicientes. La mediación es una variante alternativa y no meramente supletoria de la resolución de conflictos relativos a materias de Derecho Civil o Mercantil. La evolución de los proyectos que, bajo el rótulo de "Justicia Civil, 2007-2013”, alimenta el Programa implantado por el Parlamento y el Consejo de la UE, refleja las funciones, responsabilidades y oportunidades que, en ámbitos tan vastos como retadores, incumben a las comunidades de juristas y/o a los especialistas de disciplinas simpatizantes o tangentes con los problemas de la mediación.

Dicho Programa intenta sistematizar -ordenándole con el mejor de los propósitos- un elenco de actividades de primera magnitud que engloban cuanto afecta al creciente ejercicio de la mediación, engrandeciendo el conocimiento de una institución indispensable para el bienestar jurídico y social del empequeñecido mundo de hoy. Hay que contribuir a crear un área genuina de justicia en materias civiles y corresponder a las actitudes de reconocimiento y confianza recíproca que comparten los 27 Estados miembros de la UE. No acucia menos la urgencia de acelerar la remoción de los obstáculos con que ciertas dificultades -arraigadas en el Derecho constituido de esos Estados soberanos- anquilosan la elasticidad de los principios de contradicción y audiencia bilateral que, paliando los inconvenientes de la indefensión, afianzan la igualdad material de las partes en los procedimientos iniciados para preservar sus respectivos intereses. Es inaplazable fomentar el progreso de las actividades usuales de las personas y las comunidades, promoviendo la actuación y la defensa de sus derechos individuales y colectivos en el espacio de la UE. Se ha de asegurar especialmente el acceso a la tutela de las jurisdicciones competentes y a los cauces alternativos de solución de conflictos. Hay que multiplicar los intercambios informativos y constituir redes idóneas para estabilizar sistemáticamente los vínculos que las autoridades judiciales y administrativas mantienen con los profesionales del Derecho.

Esta serie de finalidades alienta la ilusión subyacente -común a los momentos históricos de afanosa reivindicación de la verdad y a los esfuer- 
zos hechos para ejercitarla- de regresar a las parcelas añoradas de la justicia material. Justicia cuya presencia ha oscilado entre fulgurantes conquistas y desoladores ocasos, aunque su infatigable propensión a retornar ignora el desaliento, contra el que lucha sin tregua, y no desiste de fulminar los riesgos de la marginación y/o del olvido.

El estado de cosas que justifica los ambiciosos propósitos de la UE descansa en el convencimiento de que, visto el efecto de sus antecedentes saludables, los Estados miembros se esmeran en optimizar sus experiencias, sus técnicas de conocimiento, sus recursos y sus objetivos. No les intimidan las dificultades de método y de ejecución que aquejan a una empresa de calado $\tan$ hondo. Entienden que, durante medio siglo, han construido una zona de estabilidad, democracia y desarrollo sostenible, donde, para convivir a la usanza europea, se han dado cita las diversidades culturales, el espíritu de tolerancia y el respeto a la libertad individual. La UE desea que estas adquisiciones y valores se aglutinen y subsistan al servicio de los pueblos que forman su entorno. Incluida, como es notorio y claro, la figura de la mediación y su papel de alternativa al elevado coste de los procesos judiciales.

El destaque del instituto de la mediación - efecto emblemático de aquéllas consideraciones y propósitos- aconseja garantizar los objetivos específicos de los juristas deseosos de acometer el tratamiento de los problemas que inevitablemente han de plantearse. La tarea se inicia suprimiendo los obstáculos irrazonablemente opuestos a la introducción de esas prácticas, insistiendo en la generalización de su excelencia, inventando -es decir, descubriendo- criterios comunes para llevarlas productivamente a buen fin, y excitando el fervor metodológico con que la UE aspira a popularizar el rostro afable de una técnica jurídica -aceptable desde todos los flancos- de los modos alternativos de solución de conflictos.

Merecen atención, a causa de la detenida reflexión que sus intervenciones exigen y lo ejemplar de sus iniciativas, las funciones complementarias de un órgano de orientación y de crítica que embalsa las cuestiones aportadas por los experimentos de la mediación y por una teoría lúcidamente elaborada en virtud de sus numerosos testimonios.

\section{Novedosas funciones del órgano de orientación y de crítica -denomi- nado Steering Committe - en los análisis aconsejados por el carácter y el funcionamiento de la mediación sobre cuestiones conflictivas de Derecho Civil y Mercantil}

El desempeño provechoso de las funciones centrales de un Steering Committe en los debates académicos sobre la mediación relativa a controversias de Derecho Civil y Mercantil, depende de la minuciosa atención que ha de prestarse a las intervenciones didácticas de la fase introductoria, a la presentación de las actividades mediadores con simulaciones complementarias de carácter civil y/o mercantil, y a las consideraciones teoricoprácticas que, 
en unidad de acto, formulan los componentes de la audiencia. El Steering Committé no constituye un Comité de Sabios -rotulación a que induce la exacerbación publicitaria de ciertas inclinaciones lucrativas- y sí de juristas responsables o cultivadores curiosos de disciplinas conexas con el imperio del Derecho justo, en pos del cual se sigue avanzando con fortuna variable.

La dosificación del tiempo de las intervenciones y la simultaneidad de su conocimiento -caracterizado por la inmediación oral de los oyentes- destilan un torrente de insinuaciones y propuestas tan importantes como coartadas por esas restricciones. La ulterior reflexión -pausada y coherente- sobre los aspectos de interés -única vía de abordarlas positivamente- lleva a formular tesis o proposiciones abiertas que, como las expuestas a continuación, no se pudieron enunciar entonces con el sosiego y pormenor que su naturaleza requería.

Helas aquí, tal y como el autor de este estudio -componente del órgano de orientación y de crítica que se constituyó y cumplió su papel al término de la programación precedente- tiene ahora la oportunidad de ampliarlas al hilo de la espontaneidad y celeridad con que a la sazón se formularon. Lo hace a partir de su intervención en el acto que -bajo los auspicios de la UE"JAMS INTERNATIONAL ADR CENTER" organizó, el 10 de junio de 2010, en la sede de Madrid de la UNIVERSIDAD PONTIFICIA "COMILLAS" y en el que participaron dicho Centro Universitario (ICAI e ICADE), la UNIVERSIDAD DE DEUSTO (Facultad de Derecho), la UNIVERSIDAD "RAMON LLULL" (ESADE, Law School) y AMAJE (Asociación de Jueces y Magistrados Jubilados de España).

1. La figura jurídica de la mediación supone que, al surgir una situación conflictiva en el campo de aplicación alternativa de este sustitutivo procesal, se produce la intervención de un tercero que, amén de sus aptitudes específicas, se considera imparcial e independiente de los implicados en la controversia.

2. La entrada en escena del mediador significa algo más que una serie de insinuaciones ingeniosamente preparadas para que, sin un elemental esfuerzo crítico, las partes cedan a su atractivo pacificador.

3. Los objetivos de una paz social justa y mitigadora de los antagonismos, no se alcanzan si, lejos de detenerse a mitad de camino, los interesados no agotan los esfuerzos que les incumbe desplegar en el curso de la negociación.

4. Lo sustancial de la confianza explícita en la actuación del mediador, atañe a los contenidos polémicos de las sugerencias y/o conductas que delimitan la confrontación propia de los razonamientos discrepantes.

5. La mediación obedece a un principio de tecnificación jurídica que, según la fisonomía del problema planteado, se caracteriza por la efectividad cualificada de las voluntades prestas a recibirla y practicarla.

6. Existe un ingrediente de injerencia cuando, convenidas la práctica de la mediación y las maneras de llevarla a cabo, el mediador comunica a las 
partes las iniciativas que, a su leal saber y entender, son óptimas para resolver conforme al Derecho constituido o el orden natural de la equidad.

7. El mediador ha de evacuar su gestión con el cuidado o ausencia de arrebato -que puede deberse al convencimiento de la excelencia de sus capacidades- y la atención o derroche de la sagacidad que -a juzgar por las circunstancias de las personas, del tiempo y del lugar- concurren presumiblemente en su persona.

8. El desplazamiento de las técnicas alternativas de solución de controversias civiles y/o mercantiles al campo de la mediación se justifica porque, a falta de una desjudicialización adecuada de su tratamiento, la enjundia de las disidencias produce dilaciones gravosas y sacrificios económicos.

9. Pese a las apariencias de causalidad eficiente que parecen darse en la actividad del mediador, el acuerdo final - favorecido por su asistencia $e$ insistencia- nace del concurso de voluntades o consentimiento relativo a los intereses legítimos que se predeterminan.

10. El empuje de una mediación cuasicoactiva -que parece subrogarse en las iniciativas de las partes- difiere de las ayudas persuasivas que, siguiendo la consigna "atrévete a pensar", definen una mediación socrática como clave de su cuerpo y alma.

11. La autoridad moral y jurídica de la mediación no procede de imposiciones superiores o ajenas a los rasgos de los problemas abordados, y descansa en la fuerza de impregnación intelectual, en la aptitud para racionalizar la suerte de las divergencias existentes, y en el fomento de las comunicaciones transversales que las partes deben mantener.

12. La asistencia escueta de la mediación tiene lugar cuando, asumiendo el papel causal conveniente a su participación, las partes generan los pactos interlocutorios, anteriores al acuerdo final, y asienten a los términos en que éste se materializa.

13. El mediador asistencial actúa más moderadamente que cuando lo hace por vía de injerencia, pues las intervenciones compulsivas de las partes reducen la necesidad de acaparar la actividad de propuesta o detalle de las cuestiones polémicas abordadas.

14. La ingerencia creativa y la asistencia orientadora de la mediación se predican indistintamente de los aspectos de hecho, que forjan la base del negocio, y de los aspectos de Derecho, regulados por las normas jurídicas elegidas como causas de pedir de la mediación.

15. Dicha aplicación comprende las normas positivas extraídas del ordenamiento jurídico vigente y las que provienen de la contribución de la equidad.

16. El mediador debe abstenerse de imbuir a las partes el convencimiento de que no hay, para su causa, tratamiento más satisfactorio que el del proceso de composición en que se sumergen unos y otros, pues le incumbe demostrar las ventajas de esa fórmula y ver aceptadas las razones en que su preferencia se ha fundado. 
17. Se proscribe la tiranía procedimental que, descolocando el entendimiento o la voluntad de las partes, perturba el funcionamiento de una mediación que exige la asistencia de una libertad saludable y la persuasión inseparable de lo autentico de sus motivaciones.

18. La autonomía de las partes aumenta o disminuye las divergencias de sus respectivas posiciones, según se trate de celebrar negocios jurídicos transaccionales, que atañen a toda la materia debatida, o de concatenar los negocios jurídicos condicionados que han afectado previamente a contenidos parciales de conexión imprescindible.

19. Es decisiva la actitud imparcial y objetiva de los mediadores que combinan el mordiente de las propuestas iniciales -mudables en el tracto de la mediación-con la prudencia requerida para que las partes, lejos de rehuirlas con pretextos triviales, se adhieran a las líneas de fuerza sometidas a su aceptación.

20. El mediador -aun cautivado por el afán de separar el bien del maltiene que desistir de reparos que adulteran el estado de confianza necesario para asegurar, manteniendo su velocidad de crucero, el regular funcionamiento del modo de composición utilizado.

21. La prudente actuación del mediador ha de orillar hipótesis o ideas que, lejos de favorecer la distensión del conflicto, desorientan o empañan la voluntad pacificadora de las partes.

22. La intervención del mediador va más allá de la simple interposición del conciliador, porque da entrada a un razonamiento sugestivo y obliga a ejercitar las facultades de comprensión y discurso.

23. Canoniza las iniciativas con que los interesados agrupan las piezas necesarias para la gestación del acuerdo, añadiendo sugerencias útiles o advirtiendo de los impedimentos cuya supresión condiciona el buen fin de lo que se pretende.

24. Dirige las operaciones constructivas, si echa en falta la obligada dosis de cooperación, o ayuda a construir el acuerdo, si las partes sólo formulan propuestas extravagantes o difusas.

25. Para respetar los dictados de la justicia material, el mediador puede escudriñar el comportamiento de los interesados en el curso de la mediación, reparar en sus experiencias comunicativas y recurrir a fuentes confidenciales que, en ciertos casos, debe conocer y valorar.

26. La mediación reconstituye las verdades cuya indivisibilidad proscribe el uso fragmentario de las realidades históricas y mide el impacto de los acontecimientos sobre la ponderación equitativa asociada a las preferencias de la justicia material.

27. El deber de ponderación de la equidad se extiende a cuantos casos de aplicación de las normas jurídicas -rígidas o elásticas- surjan con motivo de una mediación que acusa la necesidad de apelar a las normas del orden natural. 
28. La acción de ponderar -consistente en solidificar un concepto jurídico indeterminado casi inaprehensible- demanda algo más y distinto del examen de las reglas de Derecho objetivo, enriquecidas con la sensibilidad equitativa que presumiblemente asiste al mediador.

29. La ponderación de la equidad -que acompaña a las actividades mediadoras como la sombra al cuerpo- se predica de las contingencias relativas a los hechos cosmológicos, síquicos y sociales que, aunque ajenos a la causa de pedir primitiva de la mediación, aceleran los progresos de su espíritu móvil.

30. Este giro copernicano, obstado por el ritualismo de los procesos judiciales, responde a un principio de elasticidad que ensalza las bondades de una mediación prestigiada por la celeridad de sus efectos.

31. Semejante ampliación, en pos de soluciones adecuadas a la justicia material, complica la fisonomía de la mediación y otorga a la cualidad de mediador unos perfiles más rotundos que los de un cooperador a secas.

32. El mediador deviene un agente de liberación obligado -ante los imperativos del cambio- a suprimir las trabas que frenan los objetivos pacificadores y a impulsar los estados de cosas que razonablemente les hacen factibles.

33. El tenaz ejercicio de la mediación confirma la esperanza colectiva de que la paz social no sufra degradaciones que frustren las esperanzas puestas en el vigor y el rodaje del desarrollo sostenible.

34. La reflexión confesional postconciliar había adelantado, para aleccionamiento del pensamiento secular, que, al tiempo de promover el progreso de los pueblos, el desarrollo responsable constituía la versión modernizante de la paz y que ésta no era sólo silencio de las armas o el hueco consiguiente a la extinción de los antagonismos.

35. Las porciones de paz que garantiza el resultado positivo de los oficios mediadores, son insustituibles para mejorar la coexistencia, la colaboración y la participación de los componentes de la familia humana, revitalizando el que, a partir de la noción de bien común aristotélicotomista, lleva hoy el nombre de acervo de los intereses generales.

36. La paz, compendio de esas soluciones y de sus esfuerzos de repetición, acumula, por derecho de conquista intelectual y moral, los ideales de una humanidad más humana y prueba la excelencia de la mediación fundada en los temperamentos de equidad.

37. La frecuencia y la efectividad de los experimentos mediadores son decisivas para que, al implantarse las estructuras sociales, se encauce el torrente de las confrontaciones estériles.

38. El sensato empleo de la mediación impide confundir la fecundidad de la consigna heraclitea -según la cual "la lucha y la contradicción lo engendran todo"- con la obstinación en perpetuar la dialéctica amigo-enemigo. 
39. A medida que las operaciones estadísticas esclarecen el verdadero rostro y la fenómenología de la mediación, ésta deja de ser sólo acreedora a opiniones de bondadosa complacencia y añade cuestiones impuestas a la curiosidad de sus cultivadores.

40. El mediador se asemeja a un vicario o sustituto de hipotéticas posturas de oferta y aceptación que inauguran el ciclo de conversaciones precedentes a un negocio jurídico de remoción de disidencias y adición de precisiones complementarias.

41. Si, al finalizar este ciclo, las conformidades afluentes a la mediación no se resienten de asperezas que las entenebrecen, se concluye el negocio jurídico que reanuda el proyecto afectado por las discrepancias paralizadoras.

42. La mediación minimalista favorece y/o completa soluciones tan persuasivas y estudiadas, que el esfuerzo de disconformidad o coincidencia no expone a errores sustanciales que las invaliden.

43. El asentimiento, la desautorización o la discreta corrección de estas proposiciones, configuran una modalidad de mediación reducida a lo que estrictamente se entiende por ayuda.

44. La mediación maximalista provoca una autoría de composición en que sobresalen la causalidad adyacente de los mediadores y el interés de sus contribuciones pedagógicas.

45. Ello sucede cuando es más arduo excitar la participación de los interesados o hace falta infundirles un plus de confianza en los valores y la eficacia de la mediación.

46. La prosperidad atribuida a las acciones mediadoras padece si se olvida el destaque de determinadas circunstancias históricas, minimizando la importancia del conocimiento exhaustivo de los hechos y prejuzgando que el tratamiento jurídico de sus pormenores resuelve la totalidad de los problemas.

47. Una presentación harto escueta de los hechos cosmológicos, sicológicos y sociales no es encomiable si priva al mediador de referencias esenciales sobre la periferia o el aspecto central de la situación analizada.

48. El resultado de la reconstitución de los hechos, cuya realidad y/o causalidad se consideran, y de los que traiga a colación el mediador, ha de respetar el núcleo invulnerable del desarrollo sostenible y los postulados de la justicia material.

49. Las experiencias mediadoras y sus novedades garantizan lo que ese sentimiento tiene de insustituible para proteger los intereses legítimos de los particulares y de aleccionador para proveer a los intereses generales de la comunidad.

50. La intensidad con que los mundos circundantes propician la excelencia de la universalidad e indivisibilidad de la verdad, justifica la figura de una mediación binaria que escinde y distribuye los papeles de los mediadores.

51. El contenido de la mediación sobre los hechos atañe a los hechos cosmológicos, regidos por las leyes de la naturaleza, los hechos síquicos, 
dependientes de las disciplinas del espíritu, y los hechos sociales, expuestos a errores o paliativos de diagnóstico.

52. Dicho contenido ha de incluir cuantas apreciaciones, similares o afines a los consejos técnicos, aclaren la fisonomía del conflicto y delimiten las zonas sociales en que ha de repercutir su decisión.

53. La mediación sobre los hechos requiere que la autonomía de las partes valore los elementos periciales de convicción y prohibe suplantar el uso de las reglas de la sana crítica por el sometimiento ciego al parecer de los especialistas.

54. Las funciones ambientadoras del mediador de Derecho robustecen las potencias del alma de los interesados -memoria, entendimiento y voluntad- para asumir las peripecias históricas, comulgar con su solvente raciocinio y compartir la acogida del parecer definitivo.

55. Le compete disipar los recelos que pongan en trance de descrédito su devoción a los imperativos del orden natural, sus dotes de imparcialidad y su vocación equitativa.

56. Le corresponde estimular la disposición cooperativa que, sin mermar la integridad defensiva de las posturas de las partes, les obliga irrenunciablemente.

57. La mediación provoca más adhesiones que las que causa el arbitraje y suaviza los recelos que su práctica puede suscitar.

58. Además de la excelencia reductora de las tensiones a que afecta, el arbitraje evita la languidez y el elevado coste de los procesos judiciales, allí donde ambos inconvenientes restringen las oportunidades de garantizar el acceso a la justicia material.

59. La mediación constituye un modo de composición enriquecedor y educativo, pues pone a prueba la insistencia en el aprendizaje de la distensión, animando la coexistencia equilibrada, el espíritu creador y la participación equitativa en el goce de sus adelantos.

60. La estadística de los efectos benéficos de la mediación demuestra que los conflictos se componen obviando las formalidades superabundantes y rehusando las que estorban la pacificación apetecida.

61. Las partes son la causa eficiente del acuerdo y asumen las cargas propias de esta condición, pues los mediadores desempeñan un cometido orientador que no constituye el título jurídico de la solución obtenida.

62. Las partes han de disponer la lógica de los sucesos básicos de la mediación y ordenarlos con el acierto suficiente para que el acuerdo final -unificador y concluyente- resulte de una armoniosa coincidencia.

63. El arraigo cultural de la mediación choca con la enemiga de prejuicios endémicos, cuya terquedad y contundencia emocionales despiertan recelos agravados por la obstinación de juristas que no la reciben de buen grado.

64. El repertorio descalificador engloba las insinuaciones de los grupos de presión, la confusión de la mediación con instituciones que le son extra- 
ñas, la capitalización del miedo a la paz, la radicalización de las posturas antagónicas, la desconfianza en la imparcialidad de los mediadores y la supuesta laxitud del procedimiento.

65. La entremezcla de dichos factores promueve ambientes de acogida glacial que se contaminan socialmente y engendran prejuicios que no se esfuman de un día para otro.

66. Estas posturas dicen añorar la imparcialidad de los jueces ordinarios -elogiada si coincide con sus pareceres y censurada en el caso contrario- y deniegan el pan y la sal de su objetividad a los agentes de la mediación.

67. Lo que no ha conseguido la recepción de las esencias yusnaturalistas y/o constitucionales -a saber, el adoctrinamiento encaminado al pleno y libre desarrollo de la personalidad y los beneficios educativos del cultivo de la mediación- lo impone el estado actual de crisis económica cuya enormidad escapa a todo vaticinio.

68. La singularidad de esos cambios obliga a introducir mecanismos que, como ocurre con la mediación, dejan de ser excepcionales para graduar la hechura de los conflictos emergentes y apresurarse a moderarlos.

69. El elogio apriorístico de las excelencias de la mediación puede abundar en lugares comunes y excesos imaginativos que se depuran precisando las experiencias aptas para acreditar esa bondad.

70. Función pedagógica de la mediación es revelar a la opinión pública las ofuscaciones y medias verdades, que sirven a intereses espurios, y denunciar los vicios de la petrificación intelectual que enloda los progresos del Derecho justo.

71. Las tareas incidentales del mediador en solitario se refieren al señalamiento de caminos que, una vez abiertos y aceptados, hay que recorrer disciplinadamente para beneficiarse de su provechosa elección.

72. El mediador ha de luchar, en esas o similares circunstancias, contra la desangelada acogida de unos oficios que, si de veras no conquistan la fidelidad cooperativa de las partes, multiplican su capacidad de decepción.

73. La presentación preparatoria de las actividades mediadores puede engendrar recelos o apatías que se convierten luego en atractivos o que, al contrario, incrementan su dosis de perversidad.

74. La cosmoeminencia o dignidad de la persona humana le hace acreedora a los bienes y derechos que, según la naturaleza de las cosas, se obtienen cuando las voluntades solidarias producen los efectos pacificadores consiguientes a la mediación.

75. La libertad de la mediación como fundamento de la estabilidad colectiva, estimula la coexistencia en paz con los iguales, invita a la colaboración distributiva de los deberes sociales y asegura la participación en las consecuencias de todo ello.

76. Estos bienes son algo que el ejercicio del poder judicial no está siempre en condiciones de garantizar y que, al ser lo mejor enemigo de lo bueno, se sustituye por las -más modestas-consecuencias de la efectividad que a su protección caracteriza. 
77. Al libre desarrollo de la personalidad humana, fruto de la cultura de la mediación, se suma la carga de respetar los principios democráticos de convivencia, que habitan en un cielo moral, y la eficacia preceptiva directa de los derechos fundamentales y las libertades públicas.

78. El precio del éxito de la mediación se asocia a la verificación estadística de que una novísima creatividad renovadora - afincada en la complejidad del universo- se eleva a la segunda potencia y clama por la más amplia difusión de sus ambiciosas funciones sociales.

79. Una teoría modélica de la mediación surtirá de propuestas inéditas que, a medida del volumen que alcancen y del aliciente de su crecimiento, permitan sistematizar las actitudes y los juicios que así se manifiestan.

80. Por mucha excelencia que le otorguen los pensamientos de deseo, la información del enriquecimiento moral, social y jurídico que la mediación origina, se ha de completar con la noticia de sus fundamentos históricos.

81. Se presupone una continuidad de experiencias sujetas al principio de que la teoría no se satisface prescindiendo de la realidad y simulando sus hipótesis, sino que se complace en derramar-exponiéndola a la más demoledora de las críticas - la variedad de sus expresiones y mudanzas.

82. La conciliación arranca de una metodología pedagógica en que la tesis de la superioridad intelectual y sicológica del conciliador intenta convencer de que su propuesta es la más equitativa de cuantas pueden reequilibrar los intereses conmovidos o en trance de desaparición.

83. El crédito presunto de las soluciones deparadas por la mediación, sustituye a las consideraciones jurídicas que, en el caso de la conciliación, requieren una creatividad más liviana.

84. La conciliación compone conflictos en que, subjetivamente, se aprecia un plus de docilidad a las insinuaciones del conciliador y, objetivamente, no surgen fatigosas cuestiones técnicojurídicas.

85. Las partes inmersas en la mediación deben mantener la conciencia cooperativa de protagonismo inmediato que, por defecto, no se da en el arbitraje y, por exceso, no concurre en la conciliación.

86. Además de la síntesis equitativa que acusa su naturaleza, la mediación tiene que producir el efecto didáctico de adiestrar en los hábitos de la buena fe y la lealtad convencionales.

87. La relevancia moralizadora de esta contribución asegura niveles de rectitud y honestidad que, sin ser un lujoso aderezo, ayudan a surcar los mares de una navegación muy agitada.

88. La voluntad de diálogo crea un ambiente de inducción pacificadora que incita a una disposición de buena fe purgada de dobleces, enaltece los hábitos de rectificación y propósito de enmienda, y añade un componente de civismo contractual.

89. La eficacia mimética de los éxitos de la mediación, sirve de precedente que modera la conflictividad de situaciones iguales o análogas a las que se han beneficiado de un tratamiento equitativo. 
90. Cabe que los conflictos disminuyan por motivaciones de eficacia en que la moda del talante moralizador ( $i$ ?) suscita espectaculares reflexiones y efectos.

91. Al tiempo de defenderse la desjudicialización de algunas parcelas conflictivas, las ventajas de la mediación derivan de las particulares circunstancias que concurren en ciertas hipótesis.

92. Hay proyectos cuya envergadura se caracteriza por la unanimidad absoluta que asiste a la decisión de consumarlos, ponderar su provecho económico y cumplir sus funciones sociales.

93. La disminución de diferencias que ha de facilitar la mediación, blinda los objetivos del proyecto, fortalece su espíritu común y sirve a la voluntad de suprimir los obstáculos que se le pueden oponer.

94. El acceso a la jurisdicción, mínimo garantizador e inferior al óptimo de la protección apetecible, no acapara el salvamento de problemas cuyo embrollado tecnicismo frena el éxito definitivo de los objetivos principales.

95. Esas diferencias no son triviales y deben dilucidarse de inmediato, so pena de causar paralizaciones que inutilicen las expectativas centrales del proyecto y fuercen a desistir de continuarlo.

96. Su alegación no trata de abrir un frente rupturista que, detestando la devoción por la obra bien hecha, menosprecie lo que tan meritoriamente se ha forjado y ha de conservarse con vistas al futuro.

97. La mediación coadyuva a cerrar filas para resolver las objeciones planteadas y reanudar, en términos de recia solidaridad, las tareas temporalmente interrumpidas.

98. La modestia de muchos conflictos -solubles gracias a las actividades mediadoras- se suele complicar si el debate se defiere al conocimiento de la jurisdicción ordinaria.

99. No es bueno que el triunfo de uno de los pareceres divergentes, agravado por lo probable de los enfrentamientos personales, dependa de una judicialización que traslada a parajes de peligro desintegrador los objetivos inicialmente compartidos.

100. Así las cosas, la judicialización del problema puede ir más allá de un simple mal menor y resultar una terapia de efectos explosivos.

101. Cabe inclusive que, sin visos de recuperación, se evapore la disposición cooperativa indispensable para que la sociedad pluralista goce de las garantías de la prestación de los servicios esenciales de la comunidad.

102. Al estarse jugando con el tiempo, la lentitud del proceso judicial y la exacerbación del amor propio amenazan o hieren de muerte la naturalidad del proyecto que se ha detenido.

103. La inflación de los ritos procesales se asemeja a una fuerza mayor que, violentando el ritmo regular de las actividades afectadas, excita a la voladura controlada del espíritu de cooperación.

104. La intuición de la tardanza y de las consecuencias negativas de la judicialización no facilitan, si las tentativas procesales fracasan, el regreso a una metodología de emergencia en busca del tiempo perdido. 
105. No ha de acudirse a la jurisdicción para tratar aspectos cuya satisfacción requiere algo más y distinto de las garantías de la efectiva tutela judicial de los derechos subjetivos y los intereses legítimos que se hallan en conflicto.

106. Los reparos subsisten mientras el desarrollo del valor superior del pluralismo político no dote de las dimensiones adecuadas a este concepto jurídico indeterminado e imponga la moda cultural del elogio y la estima de la mediación.

107. Cuando no se ve ni se reacciona claro en este punto, la inesperada aparición de una disidencia incidental arruina las oportunidades de salvar las situaciones jurídicas tocadas por la discrepancia y amenaza la supervivencia de importantes funciones sociales.

108. Se ha objetado que la idoneidad de los antiguos jueces y magistrados para actuar en calidad de mediadores, se resiente de la falta del entrenamiento flexible que, mientras permanecieron en activo, no estaba a su alcance, por vedarlo su obligación de exclusivo sometimiento al imperio de la ley.

109. Una contraobjeción existencial muestra que han vivido experiencias cuyo tratamiento -natural e instintivamente equitativo- chocaba con la prohibición legal de los remedios que su sensibilidad moral y jurídica les aconsejaba.

110. Al preceptuar la ponderación judicial de la equidad, el legislador ordinario ha presupuesto que los jueces profesionales dominan sus requerimientos de base y están en condiciones de atenderlos con lucidez y suficiencia.

111. En las actuales circunstancias de tiempo y de lugar, los jueces ordinarios han de atenerse a los dictados de la razón y el buen sentido para que, sin dimitir de su sometimiento al imperio de la ley, nadie dude de su compromiso con las adquisiciones del uso equitativo del Derecho.

112. Ahí se descubre la zona expansiva de la moralidad legalizada que los imperativos éticos transmiten, en general, al afán transformador de los poderes públicos y, en especial, al decisionismo político de los legisladores ordinarios.

113. Es en estos novísimos espacios donde, como objeto emblemático de la mediación, la justicia material absorbe la igualdad y la libertad generadoras de una efectividad evidentemente superior a la que hoy se declara y santifica.

114. La elite de los procesalistas clásicos vio con buenos ojos la aportación de componentes de equidad, cercanos a las técnicas de la mediación, en los procesos restringidos de antiguo por los principios dispositivo y de aportación de parte.

115. Elogiaron la hipótesis de que, sorteando el ritualismo imperante, las decisiones judiciales zanjasen los litigios conforme a lo que, en verdad, representaba la justicia -algo compartido con los designios centrales de la mediación- y moralizaba el Derecho aplicado. 
116. Puede haber una mediación instantánea o vibratoria y una mediación gradual procedente de encadenar y/o refundir los acuerdos de voluntades que se han sucedido en su transcurso.

117. La primera acontece cuando, andando la negociación, el más reciente de los acuerdos interlocutorios colisiona con los que le preceden y rompe su línea de continuidad.

118. La mediación se llama vibratoria porque, a lo largo de sus episodios, los acuerdos logrados permanecen en levitación y sobreviven gracias a una suerte de equilibrio inestable.

119. Dicha conservación se robustece si la adopción de los demás acuerdos respeta las actitudes de sensibilidad necesarias para coordinar los avances de la negociación a los que el mediador presta su apoyo.

120. La mediación se estanca o frustra si, al interponerse esos impedimentos, los acuerdos cerrados se tienen por no concluidos y resucitan confrontaciones de creciente encono y/o esterilidad imprevisible.

121. Si la actividad del mediador no reorganiza los elementos y propósitos en pugna, el fracaso global de la mediación obliga a reiniciarla -si se quiere salvar su utilidad- como si nada hubiese ocurrido en los anteriores episodios del procedimiento.

122. El aprovechamiento de la mediación requiere entonces desandar todo o parte de lo andado, aunque el coste de las dilaciones padecidas es inferior al de las demoras de los procesos judiciales.

123. Los inconvenientes se mitigan si, para paliar esos efectos, la metodología de la mediación permite invocar la doctrina de la dislocación de la base del negocio o el régimen de las obligaciones condicionales que se han constituido.

124. Hay mediación consolidada si la lucidez de las directrices del proyecto confiere a los acuerdos interlocutorios una coherencia que no teme afrontar los riesgos de un accidentado porvenir.

125. El mediador no puede entusiasmarse con el éxito de una mediación afortunada y debe estar a las limitaciones derivadas de los mandatos y/o las prohibiciones del orden público textual o virtual que aloja el depósito del Derecho necesario.

126. Si estas exigencias se conculcan, el mediador ha de rehacer la conmutatividad de los acuerdos -que están a punto de venirse abajo- y restaurar el equilibrio amenazado.

127. El alcance de las modificaciones aducidas por el mediador-que denuncia la transgresión del Derecho necesario- puede mudar sustancialmente lo acordado y afluir a una renegociación que reponga la equidad olvidada.

128. Los escollos de las operaciones mediadoras no destruyen el espíritu de continuidad que ha de preservarse con delicadeza, absteniéndose de disentir sobre temas evidentemente inconmovibles. 
129. El resultado de la mediación abarca lo relativo a la composición satisfactoria del conflicto y, en su caso, a la constancia de la inutilidad de los esfuerzos hechos para eliminar las fricciones subsistentes.

130. Estas últimas se segregan del contenido pacificador del acuerdo y no excluyen ulteriores tentativas de composición.

131. Las variantes o especies de la mediación no son el fruto de un kantismo de laboratorio y sí de un esfuerzo sintético que opera sobre datos históricos abigarrados y confusos.

132. Cuesta lo suyo construir, con rigor sistemático, un cuerpo visible de variantes de la mediación, nacidas de los interrogantes que se deben al flujo abrumador y novedoso de sus experimentos.

133. La mediación reguladora dota de soluciones comprensibles y correctas a las cuestiones que son objeto de conformidad.

134. Los datos, tácita o explícitamente deducidos de las actuaciones mediadoras, constituyen elementos auténticos de interpretación que esclarecen las dudas relativas a la ejecución de los acuerdos adoptados.

135. El buen fin de las operaciones mediadoras aconseja incorporar cláusulas preventivas de las anomalías peligrosas para el éxito de sus resultados.

136. El desplazamiento del centro natural de gravedad de las actividades mediadoras y el quietismo de sus protagonistas, hacen de la mediación un gravamen desproporcionado para el mediador y una exención inadmisible para los demás beneficiarios.

137. Un episodio negativo de la mediación se da si el propósito de los interesados tropieza con eventos externos que, al originar su indefensión, les impiden prestar la cooperación íntegra que se esperaba de sus intervenciones.

138. Las dimensiones de un conflicto pueden crecer artificiosamente hasta el punto de que, a falta de una delimitación concienzuda, el ámbito de la mediación se transforma en un espacio inaccesible.

139. Como ministro de la equidad, que viene a ser, el mediador edifica un ordenamiento jurídico acomodado a la fisonomía del caso en que le corresponde intervenir.

140. Aun en supuestos de disidencia-límite, el mediador ha de convencer a las partes de que la menos inconveniente de las soluciones aconseja seguir las directrices del ordenamiento jurídico configurado para el caso sujeto a ese modo de composición.

141. Sin las aspiraciones utópicas de instalar el paraíso en la tierra, la mediación constituye un ejercicio de funciones públicas cuya repercusión en los intereses generales requiere ocuparse, con especial solicitud, de la formación y perfeccionamiento de sus especialistas.

142. No sólo se trata de respetar los mínimos con que el yusnaturalismo de la Unión Europea (¿?) deslinda el espacio adquirido y habitado por la comunidad de juristas dedicados al estudio teórico y a la práctica de la mediación. 
143. El Estado legislador, luego de asentar los pilares de una Política Legislativa consecuente con el prestigio que la mediación ha ganado, tiene que apresurarse a regularla.

144. Debe familiarizarse con el ingrediente cultural que suponen las garantías de una paz social devota de la dignidad y la integridad moral de las personas, con el realce del derecho fundamental a la educación, que impulsa y flexibiliza estos avances, y con las funciones sociales de la libertad de empresa en el marco de una economía de mercado.

145. Es preciso inventar una Política Legislativa que, arrostrando las aventuras del espíritu móvil, satisfaga las demandas de los procesos de cambio con los que la teoría y la práctica de la mediación están comprometidas.

146. La notabilidad de las funciones mediadoras no se limita a crear un ordenamiento jurídico equitativo para cada caso, sino que se propaga a la verdad material o fidelidad histórica de las versiones omnicomprensivas de los hechos.

147. Si se acoge la figura de la comediación, los mediadores de hecho intentan rescatar verazmente los acontecimientos del pasado y emprender la denuncia profética de las situaciones indeseables que, en el futuro, pueden dañar los intereses defendidos.

148. La posesión de estas cualidades y la convicción de su provecho informan el cuerpo del Derecho de Gentes de la mediación, cuya doctrina general obedece a dos órdenes de consideraciones.

149. La una concierne a la importancia que el hallazgo de la verdad material de los hechos representa para el crédito de una mediación que, por iguales partes, detesta el dogmatismo de lo convencional y lo enfermizo del garantismo a ultranza.

150. La otra enseña que la teoría no mejora aumentando la lista de sus vaporosos ideales y que se enriquece cuando, sumida en las compactas realidades de la mediación, explota el repertorio de los hechos probados que autorizan a razonar y concluir.

151.Estas reflexiones dan lugar a que la Filosofía y la Ciencia del Derecho arrinconen los esoterismos de la técnica jurídica tradicional y comulguen con el lenguaje equitativo y comprensible de las especialidades mediadoras.

152. La consideración de la mediación como ayuda o asistencia elemental del mediador no agota sus horizontes conceptuales, pues le acompaña un mal de crecimiento cuyos bienes y avances se persiguen y tratan de localizarse.

153. Ayudar no es sólo enderezar las voluntades de las partes, que aceptan las sugerencias recibidas para enmendar sus equivocaciones o hacen caso omiso de la asistencia que se les ofrece.

154. Ayudar significa acotar los espacios en que, gracias al juego de las energías mediadoras, las voluntades conflictivas no incurren en errores de base cuando encaran las situaciones de hecho y de Derecho que el entendimiento debe comprender y definir. 
155. Las voluntades conflictivas que disfrutan de esta asistencia reforzada -pues cabe hablar de mediación de dos o más velocidades- desarrollan una autonomía enriquecida por los apoyos conseguidos y resuelta a mejorar la calidad de la justicia material a que propenden sus intervenciones.

156. Al mediador conviene la denominación de administrador de las incidencias o episodios análogos que, sucediéndose en el tiempo, aproximan al consentimiento final prestado por las partes.

157. Como contrafigura de los consensos equívocos y/o depauperados, la solidez y ausencia de fisuras - con que el mediador organiza las declaraciones de conocimiento y voluntad de las partes- fortalece el acuerdo sustitutivo de la sentencia judicial.

158. Se pregunta cómo estructurar la mediación en las relaciones colectivas de trabajo, donde el conflicto industrial se disuelve a causa de la saña globalizadora que dispersa geográficamente los factores productivos $\mathrm{y}$ deprime la autonomía de los poderes sindicales.

159. Las normas rectoras de la mediación no constituyen un remedio supletorio de la tutela jurisdiccional atribuida al Estado social y democrático de Derecho, pero encarnan una forma de decisionismo político que fluye de un valor superior del ordenamiento jurídico.

160.Lejos de implicar un último recurso, la mediación refleja un estado de conciencia colectivo que opta por lo que, a todas luces, parece preferible y urgente, y condena la resignación residual a prescindir del bien escaso que sigue siendo la justicia.

161. El respeto a los compromisos de transformación requiere situar el tratamiento de la mediación en los niveles formativos de los títulos de enseñanza postsecundaria universitaria del Derecho y otras especialidades que notoriamente lo demanden.

162. Las tareas de edificación y coextensión del Espacio Europeo de Enseñanza Superior exigen la contribución necesaria para que, gracias a la enseñanza y el aprendizaje, los juristas y la sociedad se familiaricen con el cuerpo y el alma de la mediación.

163. Hay que "decir no" a una inclusión ornamental o secundaria de la mediación en los niveles formativos, donde han de primar una curiosidad y devoción excepcionales para con lo que este sustitutivo procesal es y significa.

164. Lejos de figurar como pariente pobre en el elenco de los equivalentes jurisdiccionales, la mediación es el óptimo recomendable para que los aspectos economicistas de las relaciones humanas conserven una imagen amable y exenta de crudezas superabundantes.

165. El advenimiento de la mediación al espacio público europeo, pendiente de completar su estructura, revive, guardadas las distancias, la tesis de que esa difusión reitera lo que, al emerger los Estados Nacionales, supuso la unidad de jurisdicción como reflejo de la unidad de soberanía en el terreno procesal. 
166. La mediación se adueñará de unos espacios cuya configuración óptima está pendiente de delimitarse, ya que algunos de los portadores de la consigna europeísta pecan de lo contrario y no dan muestras de un arrepentimiento convincente.

167. La mediación no se ha pensado para apoyar la tendencia a conformarse con las metas economicistas y mantener la espesura de los nacionalismos. Comparte el apasionamiento conceptual con que las más entusiastas preferencias en pro de la integración europea siguen alimentando una ilusión. La de que, quizás algún día, se actualicen los desafíos y los sueños -inspirados en la justicia material-de erigir una Europa distinta y, a la vez, igual a si misma. Una Europa donde, entre otras asignaturas pendientes, no haya lugar a reprochar la cobardía que, hoy por hoy, enmudece las voces de cuantos -sin el más mínimo sonrojo- se abstienen de denunciar y corregir, pudiendo hacerlo, los desmanes perpetrados contra la vida y los derechos de quienes forman parte de la humanidad más desvalida e indefensa.

168. A medida que se elogian las adquisiciones y se denuncian los efectos perversos de las innovaciones tecnológicas, hay que precaverse contra aquellos de sus adelantos que, aunque satisfactorios de momento, empobrecen los hábitos autónomos de conocimiento y comprensión.

169. El factor de la mediación contribuye al regular funcionamiento del mercado interior, donde puede innovar, con perspectivas óptimas, las más recientes fórmulas de pacificación que sus experiencias han dado a conocer.

170. El Derecho constituido no impone a los Estados miembros de la UE la financiación de las organizaciones mediadoras, pero las obligaciones naturales de los poderes públicos -inherentes al esfuerzo de transformación- invitan a corregir la amnesia con que la elasticidad del decisionismo político permite hacer caso omiso de esa carga y de otras no menos urgentes.

Estas y cuantas otras consideraciones -susceptibles de revisión y censura- traen causa del vértigo de la mediación, son insinuaciones que, ante los requerimientos del discurso jurídico y las habilidades anejas al progreso de aquélla, aumentan la curiosidad de la que -a causa de su voluminosa demanda- se ha dado en llamar técnica del pensamiento de problemas.

\section{Consideración conjunta de las peripecias y destaque actual del insti- tuto de la mediación}

Las coordenadas del momento histórico que refleja la práctica de la mediación civil y mercantil, permiten escrutar las corrientes contradictorias y los interrogantes motivados por la solución de los conflictos que en ese ambiente se suceden. Cuando la mediación atañe a la suerte de unas libertades de eminente contenido patrimonial o conexas con las condiciones generales de la economía, su ejercicio no puede contentarse con predicar y promover la paz inerte y desalmada que dista de satisfacer el todo de la justicia 
que se ansía. Conviene recordar que la paz no es solamente el arrinconamiento de las armas ni el vacío que la guerra deja cuando las armas han enmudecido. Aunque la mediación garantiza cierta seguridad provisional para la pacificación y el desarrollo positivo de las situaciones afectadas, no se agota con la victoria doméstica de sus logros, ya que sus éxitos generan sucesivos problemas que, como fruto de la prosperidad creadora, se multiplican en número y aumentan insoslayablemente de tamaño. Ante los apremios de futuro, la mediación ha de infundir su nueva savia a los derechos e intereses legítimos que, remozados y supervivientes, siguen expuestos a interferencias y fricciones cuando, más tarde o más temprano, lo impone la fuerza de las cosas.

La mediación no pretende -so pena de abdicar de su acervo de funciones sociales y del espíritu de modernidad que, para su gobierno, le acompaña- instalar estados de cosas exclusivamente atentos a los imperativos solidarios, al desinterés absoluto y a la generosidad irrestricta. Se privaría a los ámbitos economicistas -donde sus operaciones acaecen y abundan- de los incentivos latentes en las pretensiones de cuantos, al amparo de las normas jurídicas, no esconden su avidez -legítima, en principio, y ocasionalmente exagerada- por apropiarse y gozar de la utilidad de los bienes sensibles de la vida. Confirman esta idea los fenómenos de la producción del Derecho objetivo, la conflictividad de los episodios de su aplicación y la elección de los medios que preservan el equilibrio inestable de la paz jurídica.

La mediación relativa a las cuestiones polémicas de los sectores civil y mercantil del ordenamiento jurídico general, acondiciona los conflictos de intereses en que la voluntad de conseguir la más equitativa de las soluciones viables justifica el esfuerzo de cimentar un ordenamiento jurídico doméstico y proveer a las confrontaciones en que cada supuesto clama por su particular regulación. La mediación no canoniza soluciones que, a la usanza de la paz perpetua, responden a la clave de las utopías y comparten lo que de irrealizable tienen éstas.

La creatividad presupone la confrontación y es fuente de disidencias que -argüidas con crudeza variable y templadas con fórmulas de composiciónmantienen los riesgos sin cuya localización y voluntad de superarlos decae la fe depositada en las adquisiciones del progreso. Recuérdese cómo el ideal marxista del fin de la historia se propuso, sin éxito, eliminar unos estímulos fascinantes para cuantos -que eran legión- se aferraban a la ilusión de conocer, decidir y obrar en libertad. La mediación civil y mercantil devuelve a parte de las relaciones de ese signo la normalidad imprescindible para que, sin expulsarse de su esfera, perduren los acicates del cambio social y, luego de resolverse unos conflictos, sobrevengan otros más retadores y complejos, pero siempre abiertos a la distensión asegurada por el ritmo regular del desarrollo sostenible.

Los conflictos resueltos por la mediación forman parte del haz de intereses de los individuos y los grupos sociales que la obstinación teórica del 
marxismo redujo a términos de clase, pero que se reiteran en las escenificaciones apreciables. No se reacciona con delicadeza si, advertidas estas disfunciones, se les aplica un tratamiento de liquidación y se sacrifica a la parte más débil o castigada por los acontecimientos. El estudio denso de la mediación y el crédito de su práctica propugnan una técnica de orientación selectiva que, lejos de rechazarlas de plano, acoge las soluciones triunfalistas que, no siendo rabiosamente incompatibles, permiten armonizar las innovaciones de antes y después.

A medida que consta lo efectivo de sus experiencias, la mediación conquista espacios de conformidad en que la voluntad expansiva de progreso destruye lo irrazonable de las objeciones -poco inteligentes- que se le oponen y pierden consistencia. De estos espacios de cohesión social-debidos al arte de la mediación- arranca la inquietud transformadora que se asocia al espíritu móvil de las ofertas de otros factores concurrentes.

Ser lúcido implica concebir la mediación como un útil pacificador de conflictos cuya disolución, lejos de asegurar una paz infecunda y estática, alienta reconfortantes perspectivas. Se desnaturaliza el aforismo que -avalado por el testimonio de los supuestos poseedores de la sabiduría- declaraba que la paz era indeseable, porque aniquilaba el impulso de las libertades, ensombrecía su entusiasmo y apagaba la creatividad. Conclusión que se desbarata ante la idea de que las formas estáticas de paz son engañosas y han de superarse con los auxilios de una justicia material que exige compromisos permanentes y, si se quiere, heroicos, para proseguir la tarea de edificar una humanidad más humana.

Por si estas consideraciones fueran pocas, la relevancia de la mediación crece ante las necesidades de reajuste demandadas por una mundialización que obedece a los cambios políticos, al potencial de las informaciones veraces y/o mendaces y a la emergencia de las corporaciones multinacionales.

La mediación desarrollada en esos ámbitos coopera a las reacciones éticas de transformación que, fieles al llamamiento de la justicia material, animan las revoluciones venidas de lo alto -apoyadas por los poderes públicos- y combaten los excesos del liberalismo salvaje. Un mal que, pese a la denuncia de sus demasías, no desiste de acreditar su capacidad devastadora frente a las ventajas de la interdependencia que exhiben las adquisiciones del progreso.

\section{Bibliografía de orientación}

ALVAREZ, I. El futuro de la mediación preprocesal. Madrid: Ed La Ley, 2007.

ALVAREZ, M. "La mediación en asuntos civiles y mercantiles", Revista del Poder Judicial, n. ${ }^{\circ}$ 77, 2005, pp. 243-304.

CANEDO, M.P., DE PALO, G., MOLINA, M.C. et al. Mediation in civil and commercial disputes. Madrid Ed: Universidad Pontificia "COMILLAS", 2010. 
CIURANA, B.A. "La mediación civil y mercantil; una asignatura pendiente en España", Actualidad Jurídica (U.\&M.), n. ${ }^{\circ} 12,2005$, pp. 42-56.

COMISION DE LAS COMUNIDADES EUROPEAS. Libro Verde de 19.04.02 sobre las alternativas de solución de conflictos en el ámbito del Derecho Civil y Mercantil. Bruselas: Ed. los autores, 2002.

-Propuesta de Directiva del Parlamento Europeo y del Consejo de la Unión Europea de 22.10.04 sobre ciertos aspectos de la mediación en asuntos civiles y mercantiles. Bruselas: Ed. Diario Oficial de la Unión Europea, 25.10.04.

CHIOVENDA, G. Instituciones de Derecho Procesal Civil, traducción de GOMEZ ORBANEJA, E., v. III. Madrid: Ed. Revista de Derecho Privado, 1948.

FISHER, R. Getting to yes. Middlesex: Ed. Penguin Books, 1981.

GEMME España. La Directiva Comunitaria sobre mediación. Madrid: Ed. los autores, 2010.

GIDDENS, A. Sociología, traducción de CUELLAR, J. Madrid: Ed. Alianza Editorial, 2002.

GIL, R. La Directiva de mediación en la Comunidad Europea. Madrid: Ed. LEX, 2010.

GONZALEZ, C. Manual de mediación. Barcelona: Ed. Atelier, 2001.

LECLERCQ, J. Du droit naturel a la sociologie. Lovaina: Ed. Spes, 1960.

LURIA, A. The nature of human conflicts. Nueva York: Ed. Liveright, 1932.

NAVARRO, E. "El Proyecto de Directiva de mediación y la mediación comercial internacional", Actualidad Jurídica (U.\&M.), n. ${ }^{\circ}$ 12, 2008, pp. 26-41.

PARLAMENTO EUROPEO y CONSEJO DE LA UNION EUROPEA. Directiva del Parlamento Europeo y del Consejo de la Unión Europea de 21.05.08, sobre ciertos aspectos de la mediación en asuntos civiles y mercantiles. Bruselas: Ed. Diario Oficial de la Unión Europea, 24.05.08.

RODOTA, S. La vida y las reglas: Entre el Derecho y el no Derecho, traducción de PIÑAR, J.L. Madrid: Ed. Trotta, 2010.

VIEWEG, T. Tópica y jurisprudencia, traducción de DIEZ PICAZO, L. y prólogo de GARCIA DE ENTERRIA, E. Madrid: Ed. Taurus, 1964.

ZORRILLA, M.M, "Eficacia y justicia del orden natural de la equidad", Estudios de Deusto, v. 57/2, 2.009, pp. 255-302. 